\title{
ORIGINAL RESEARCH-SURGERY
}

\section{Prospective Evaluation of Patient Satisfaction, and Surgeon and Patient Trainer Assessment of the Coloplast Titan One Touch Release Three-Piece Inflatable Penile Prosthesis}

\author{
Dana A. Ohl, MD, ${ }^{\star}$ Gerald Brock, MD, FRCSC, ${ }^{\dagger}$ David Ralph, BSc, MS, FRCS(Urol), ${ }^{\ddagger}$ \\ William Bogache, MD, ${ }^{\S}$ LeRoy Jones, MD, " Ricardo Munarriz, MD, ${ }^{* \star}$ Laurence Levine, MD, ${ }^{\text {t† }}$ and \\ Chad Ritenour, MD护 \\ *Division of Sexual and Reproductive Medicine, Department of Urology, University of Michigan, Ann Arbor, MI, USA \\ †Department of Surgery, Division of Urology, University of Western Ontario, London, ON, Canada; ${ }^{\ddagger}$ St. Peter's Hospital \\ and the Institute of Urology, University College London, London, UK; `Carolina Urologic Research, Myrtle Beach, SC, \\ USA; "Urology San Antonio, San Antonio, TX, USA; ${ }^{* \star}$ Boston Medical Center, Boston, MA, USA; ${ }^{+\dagger}$ Department of \\ Urology, Rush University Medical Center, Chicago, IL, USA; 执epartment of Urology, School of Medicine, Emory \\ University, Atlanta, GA, USA
}

DOI: 10.1111/j.1743-6109.2012.02819.x

\begin{abstract}
A B S T R A C T
Introduction. A single-armed, prospective, multicenter international study evaluated the redesigned Coloplast Titan One Touch Release (OTR) pump inflatable penile prosthesis. The OTR pump has a unique release valve that permits deflation of the implant with one squeeze of opposing touch pads.

Aims. To assess the impact of a new penile prosthesis design, the Titan OTR, on patient ease of operation. Furthermore, to assess patient satisfaction, surgeon acceptance, and the ease with which patients were trained in device operation in the clinic setting.

Methods. A total of 113 eligible patients from eight centers were recruited from men presenting with erectile dysfunction without prior prosthetic implantation. The subjects had a mean age of 61 years, and had a number of comorbidities, including diabetes (31.9\%), hypertension (34.5\%), and Peyronie's disease (23.9\%). All underwent implantation of the study device.

Main Outcome Measures. Questionnaires were used to capture patient satisfaction as well as physician feedback on ease of implantation and patient education. A paired analysis was completed for patient satisfaction at $6(\mathrm{~N}=96)$ and $12(\mathrm{~N}=90)$ months.

Results. Overall satisfaction with the device was $90.6 \%$ and $90.0 \%$ at 6 and 12 months, respectively. The primary end point, ease of deflation, was seen in $70.8 \%$ and $73.3 \%$ at these two time points, with the 12 -month value statistically better than historical controls. Physicians overwhelmingly reported straightforward/simple intraoperative product preparation (97.3\%) and equivalent or easier training compared with their previous pump of choice (96.4\%). Adverse events for all subjects $(\mathrm{N}=113)$ included removal of the device in four cases $(3.5 \%)$ for infection and one case for chronic pain $(0.8 \%)$.

Conclusions. The Titan OTR represents an advance in penile prosthetic technology that is well accepted by patients and physicians. The study design allowed for realistic evaluation of the new technology aimed at enhancing clinical outcomes. Ohl DA, Brock G, Ralph D, Bogache W, Jones L, Munarriz R, Levine L, and Ritenour C. Prospective evaluation of patient satisfaction, and surgeon and patient trainer assessment of the Coloplast Titan One Touch Release three-piece inflatable penile prosthesis. J Sex Med 2012;9:2467-2474.
\end{abstract}

Key Words. Erectile Dysfunction; Three-Piece Inflatable Penile Prosthesis; Patient Satisfaction; Surgical Treatment 


\section{Introduction}

$\mathrm{E}$ rectile dysfunction (ED) is a prevalent condition. The Massachusetts Male Aging Study estimated that $52 \%$ of men aged $40-70$ suffered from some degree of erectile impairment [1]. In a large survey of men of all ages in the United States, Laumann et al. found that the incidence of clinically significant ED was 7\% in men aged 18-29 and rose to $18 \%$ in men aged $50-59$, trailing premature ejaculation, which was the most common sexual dysfunction seen in the survey [2]. ED has many causes, including vascular inflow disease, veno-occlusive dysfunction, neuropathy, and psychogenic issues.

Medical management of ED was vastly improved with the introduction of the type 5 phosphodiesterase inhibitors in 1998 [3]. However, efficacy rates with these agents only range from $60 \%$ to $70 \%$ at best, and poorer results are seen in men with diabetic neuropathy and those who have undergone radical prostatectomy [4]. In many men, other treatments, including intraurethral alprostadil, penile injection therapy, and vacuum constriction devices, are needed [5]. All these treatments have advantages and disadvantages. Furthermore, patient acceptance of those medical treatments varies widely.

Since the introduction of the inflatable penile prosthesis (IPP) by Scott et al. in the 1970s [6], there have been multiple modifications in device design. Device failures during the early experience were numerous, and most of the device modifications have been successful efforts directed toward increasing the mechanical reliability of the implants $[7,8]$. The most recent revision of the device described in the current paper is aimed to improve the ease of inflation and deflation of the device.

\section{Aims}

The purpose of this study was to determine the impact of a new penile prosthesis design, the Coloplast Titan One Touch Release (OTR; Coloplast Corporation, Minneapolis, MN, USA), on patient ease of operation. Furthermore, we sought to determine patient satisfaction, surgeon acceptance, and the ease with which patients were trained in device operation in the clinic setting.

\section{Methods}

A total of 113 eligible patients dispersed over eight sites underwent implantation of the Titan OTR
IPP from November 2007 to April 2009 in this prospective, non-randomized, international multicenter clinical trial. Surgical technique was determined by the individual surgeon and did not vary from typical implantation procedures. The study is prospective in nature, therefore limiting selection bias via adherence to predefined inclusion and exclusion criteria. Eligibility criteria included men at least 18 years of age willing to undergo implantation of a device to treat ED. Patients with compromised immune systems, active genitourinary infection, and severe coagulopathies were among those excluded from the study. Those who had previous devices implanted for ED were also excluded. All protocols received institutional review board approval, and all patients signed informed consent documents to participate in the study.

The Titan OTR prosthesis is a three-piece implant that involves cylinders placed in the corpora cavernosa of the penis, a pump placed in the scrotum, and a reservoir placed in the abdominal cavity of the patient (Figure 1). The entire device has a hydrophilic coating that rapidly absorbs aqueous solutions when soaked, and the cylinders and reservoir are manufactured from silicone and Bioflex (Coloplast Corporation). The hydraulic OTR pump transfers fluid between the cylinders and reservoir to allow for rigidity (inflation) and flaccidity (deflation) of the penis as appropriate.

The OTR pump has a unique release valve that permits deflation of the implant with one squeeze of the opposing touch pads (Figure 2). The size of the new pump is similar to the previous model. When the deflate mechanism is activated, the valve only allows fluid to be transferred from the

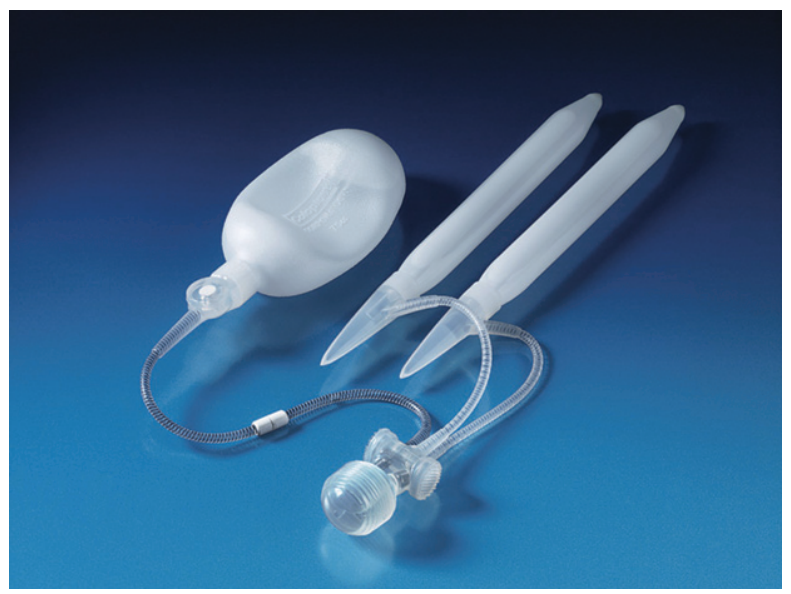

Figure 1 Titan One Touch Release three-piece penile prosthesis 


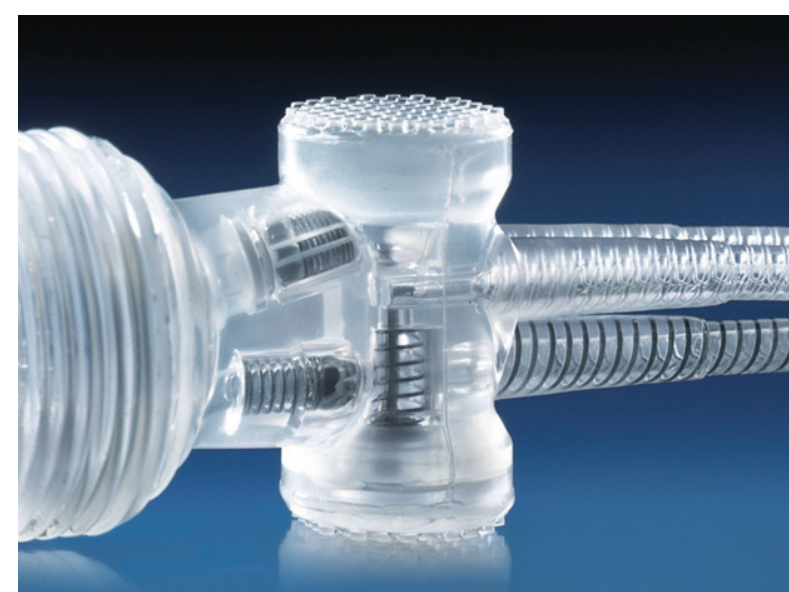

Figure 2 One Touch Release pump

cylinders to the reservoir. After activation, the pump is locked in the deflate function, preventing the need for continuous pressure to allow the flow toward the reservoir. The OTR pump's predecessor required constant pressure to be held on the deflation pads during the deflation process, and the need for constant pressure was a consistent complaint of patients. The cost difference between the OTR pump and its predecessor is approximately US \$200.

Subjects and implanting surgeons completed baseline questionnaires, and data were collected by questionnaire at 6 weeks, 3 months, 6 months, and 12 months after implantation. Data were compiled, and standard statistical analyses were performed using SAS version 9.1 or above (SAS Institute, Cary, NC, USA) or another validated statistical software package.

\section{Main Outcome Measures}

The primary end point of the study was to assess the satisfaction with ease of deflation of the OTR pump at 6 months by subject questionnaire. Retrospective data from three comparator trials were used to create a weighted average of $64 \%$ for patient satisfaction with pump deflation as a threshold with which to compare the current study [9-11]. The primary end point is a binomial proportion of participants completely or mostly satisfied with deflation performance, similar to the criteria for satisfaction reported in the comparator studies. The end point was constructed as a onesided test with a 0.05 alpha level and was analyzed by comparing the lower bound of the two-sided $90 \%$ confidence interval with the performance goal of $64 \%$.
Assuming a true (expected) rate of satisfaction of $76 \%$, an alpha level of 0.05 and a one-sided hypothesis test, this design provides $80 \%$ power to achieve the study objective with a total enrollment of 92 participants. Allowing for 20\% participant attrition (participant lost to follow-up, participant death, visits outside the follow-up window), 115 participants needed to be enrolled to reach the minimum sample size of 92 .

Secondary end points included overall satisfaction measures of the patient, implanting surgeon, and trainer. These were reported with standard statistical descriptions. For continuous variables, means, standard deviations, and confidence intervals were reported while categorical variables were summarized with frequency distributions. Adverse event data were reported and tabulated from all sites. Events were reported as procedure or devicerelated and classified based on severity.

\section{Results}

\section{Patient Population}

One hundred twenty-four patients signed consent forms for the study, but 9 were not implanted due to medical reasons, withdrawal of consent or lack of device availability, and 2 were excluded from analysis after it was determined they did not actually meet inclusion/exclusion criteria at baseline. The 113 patients included in the study were recruited from eight sites, including six in the United States, one in Canada, and one in the United Kingdom. Median enrollment per site was 13.5 patients, and no site was permitted to implant more than 25 patients. At 6 and 12 months there were 96 and 90 subjects available for analysis, respectively.

The patient population baseline characteristics are shown in Table 1 . The primary cause of ED was vascular disease and/or diabetes in more than half the group. Of note, $34.5 \%$ of the patients had abnormal curvature of the penis, with $23.9 \%$ reported as having evidence of Peyronie's disease. Prior ED treatments were given in all the subjects. These included oral medications $(97.3 \%)$, penile injection therapy $(63.7 \%)$, vacuum device (31\%), intraurethral suppository (19.5\%), and testosterone administration $(5.3 \%)$.

\section{Surgical Data}

All patients received preoperative and postoperative antibiotic prophylaxis. Furthermore, all devices were soaked in antibiotic-containing 
Table 1 Demographics and baseline characteristics

\begin{tabular}{|c|c|c|c|}
\hline Characteristic & $\mathrm{N}$ & mean $\pm \mathrm{SD}$ or $\%(\mathrm{n} / \mathrm{N})$ & Range \\
\hline Age (years) & 113 & $61.0 \pm 9.1$ & $(34.5,81.2)$ \\
\hline BMI $\left(\mathrm{kg} / \mathrm{m}^{2}\right)$ & 113 & $29.4 \pm 5.0$ & $(18.4,45.9)$ \\
\hline \multicolumn{4}{|c|}{ Primary indications (not mutually exclusive) } \\
\hline Vascular disease & 113 & $34.5 \%(39 / 113)$ & \\
\hline Diabetes mellitus & 113 & $31.9 \%(36 / 113)$ & \\
\hline Post-cancer treatment & 113 & $26.5 \%(30 / 113)$ & \\
\hline Pelvic surgery & 113 & $8.8 \%(10 / 113)$ & \\
\hline Neurogenic & 113 & $4.4 \%(5 / 113)$ & \\
\hline Psychological causes & 113 & $4.4 \%(5 / 113)$ & \\
\hline Pelvic trauma & 113 & $4.4 \%(5 / 113)$ & \\
\hline latrogenic & 113 & $0.9 \%(1 / 113)$ & \\
\hline Other & 113 & $31.9 \%(36 / 113)$ & \\
\hline Peyronie's disease & 113 & $23.9 \%(27 / 113)$ & \\
\hline Curvature abnormal & 113 & $34.5 \%(39 / 113)$ & \\
\hline Stretched penile length $(\mathrm{cm})$ & 106 & $11.9 \pm 2.5$ & $(6.0,19.0)$ \\
\hline Single sexual partner & 113 & $63.7 \%(72 / 113)$ & \\
\hline
\end{tabular}

$\mathrm{SD}=$ standard deviation; $\mathrm{BMI}=$ body mass index

solution prior to implantation. The choice of antibiotic solution was based on individual surgeon preference. The data on individual surgeon preference were not recorded. A penoscrotal approach was used in $98 \%$ of cases, and operative time averaged $61.5 \pm 22.6$ minutes. Average cylinder length was $15.9 \pm 2.0 \mathrm{~cm}$, and reservoir volume $74 \pm 11 \mathrm{~mL}$. The average length of rear tip extenders was $1.9 \mathrm{~cm}$, and in 16 subjects, no rear tip extenders were utilized. The pump was placed in the midline in $95 \%$ of cases, dartos pouch in $78 \%$, and $65 \%$ were surgically secured in place to prevent migration. Devices were universally filled with normal saline, and a surgical drain was placed in $47 \%$ of cases.

\section{Surgeon's Assessment of New Device}

Surgeons were asked to answer three questions regarding the intraoperative experience with the device. In $97.3 \%$ of the cases, the surgeon agreed that the implant preparation was straightforward. The surgeons felt that in $89.4 \%$ of the cases, the OTR pump was easier to prepare than their previous pump of choice. It was determined that the patient's scrotum was easily able to accommodate the pump placement $97.4 \%$ of the time. In all of the above queries, if a positive response was not given, the response was neutral. In no case was a negative impression of the device reported.

\section{Trainer's Assessment of the Device Activation Session}

At the 6-week follow-up appointment, patients were trained in the operation of the device. The person administering the training session, who was usually a clinic nurse, was asked to fill out a questionnaire regarding their impression of the session. The results are shown in Table 2. As one can see, the trainers felt that the vast majority of men found the device somewhat/very/extremely easy to find the inflation and deflation mechanism and to operate the device. Ninety-nine point one percent of subjects reported to the trainer that they liked the pump. The practitioners felt that $97.2 \%$ of subjects found the operation of the device easy to learn, and in comparison with prior device training experience, the subject training with the OTR pump was easier than previous pumps $99.1 \%$ of the time.

\section{Primary End Point Assessment}

The primary end point in the study was patient ease of deflation at 6 months, at which time $70.8 \%$ found the ease of deflation to be satisfactory or somewhat satisfactory. When compared with historical controls, as described earlier (64\% from pooled studies), the increase in satisfaction demonstrated a trend for improved satisfaction, but did not reach statistical significance (lower 95\% confidence limit $62.7 \%, P=0.082$ ). When analyzing this end point at 12 months, the satisfaction rate rose to $73.3 \%$, and this value was statistically significant to the $64 \%$ seen in historical controls (lower 95\% confidence limit 65\%, $P=0.033$ ).

It is also important to point out that many subjects were neutral on ease of deflation at 6 and 12 months. The numbers of men who were neutral or satisfied with ease of deflation at the two time points were $83.3 \%$ and $80.1 \%$, respectively, with a minority reporting dissatisfaction $(16.7 \%$ and $19.9 \%$, respectively). 
Table 2 Clinician/trainer 6-week questionnaire

\begin{tabular}{|c|c|c|}
\hline Characteristic & $\mathrm{N}$ & $\%(n / N)$ \\
\hline \multicolumn{3}{|c|}{ It was easy for the subject to find the inflation bulb? } \\
\hline Not at all & 108 & $0.0(0 / 108)$ \\
\hline A little & 108 & $0.9(1 / 108)$ \\
\hline Somewhat & 108 & $4.6(5 / 108)$ \\
\hline Very & 108 & $13.9(15 / 108)$ \\
\hline Extremely & 108 & $80.6(87 / 108)$ \\
\hline \multicolumn{3}{|c|}{ It was easy for the subject to find the deflation touch pads? } \\
\hline Not at all & 108 & $1.9(2 / 108)$ \\
\hline A little & 108 & $3.7(4 / 108)$ \\
\hline Somewhat & 108 & $9.3(10 / 108)$ \\
\hline Very & 108 & $26.9(29 / 108)$ \\
\hline Extremely & 108 & $58.3(63 / 108)$ \\
\hline \multicolumn{3}{|c|}{ It was easy for the subject to inflate the device? } \\
\hline Not at all & 108 & $1.9(2 / 108)$ \\
\hline A little & 108 & $0.9(1 / 108)$ \\
\hline Somewhat & 108 & $4.6(5 / 108)$ \\
\hline Very & 108 & $17.6(19 / 108)$ \\
\hline Extremely & 108 & $75.0(81 / 108)$ \\
\hline \multicolumn{3}{|c|}{ It was easy for the subject to compress the deflation touch pads? } \\
\hline Not at all & 108 & $2.8(3 / 108)$ \\
\hline A little & 108 & $1.9(2 / 108)$ \\
\hline Somewhat & 108 & $10.2(11 / 108)$ \\
\hline Very & 108 & $25.9(28 / 108)$ \\
\hline Extremely & 108 & $59.3(64 / 180)$ \\
\hline \multicolumn{3}{|c|}{$\begin{array}{l}\text { Subject training with OTR pump was easier than with previous } \\
\text { pump? }\end{array}$} \\
\hline Not at all & 108 & $1.9(2 / 108)$ \\
\hline A little & 108 & $1.9(2 / 108)$ \\
\hline Somewhat & 108 & $16.7(18 / 108)$ \\
\hline Very & 108 & $16.7(18 / 108)$ \\
\hline Extremely & 108 & $63.0(68 / 108)$ \\
\hline \multicolumn{3}{|c|}{ The OTR pump was easy to use at 1 st cycling? } \\
\hline Not at all & 108 & $1.9(2 / 108)$ \\
\hline A little & 108 & $5.6(6 / 108)$ \\
\hline Somewhat & 108 & $8.3(9 / 108)$ \\
\hline Very & 108 & $21.3(23 / 108)$ \\
\hline Extremely & 108 & $63.0(68 / 180)$ \\
\hline \multicolumn{3}{|c|}{ The subject likes the OTR pump? } \\
\hline Not at all & 108 & $0.9(1 / 108)$ \\
\hline A little & 108 & $3.7(4 / 108)$ \\
\hline Somewhat & 108 & $13.0(14 / 108)$ \\
\hline Very & 108 & $20.4(22 / 108)$ \\
\hline Extremely & 108 & $62.0(67 / 108)$ \\
\hline \multicolumn{3}{|c|}{ How easy was it for the subject to learn? } \\
\hline Not at all & 107 & $2.8(3 / 107)$ \\
\hline A little & 107 & $8.4(9 / 107)$ \\
\hline Somewhat & 107 & $7.5(8 / 107)$ \\
\hline Very & 107 & $29.9(32 / 107)$ \\
\hline Extremely & 107 & $51.4(55 / 107)$ \\
\hline
\end{tabular}

OTR $=$ One Touch Release

\section{Secondary End Point Assessment}

Table 3 shows patient satisfaction with various aspects of the device at 6 and 12 months. As one can see, satisfaction rates in all parameters exceeded $68.9 \%$, with a large proportion of other responses remaining neutral. The lowest rates were seen with ease of deflation, as discussed in the previous section, and length when inflated, a commonly stated disappointment with all penile implant patients. At 6 and 12 months, 90.6\%/90\% of patients were satisfied with the overall function of the device. At 12 months, $86.7 \%$ stated they would proceed with the operation again, and 94.5\% were either neutral or positive when asked the question. Eighty-seven point eight percent would recommend the device to other men with $\mathrm{ED}$, with $95.6 \%$ remaining at least neutral.

\section{Adverse Events}

Table 4 shows the total reported adverse events during the study. The serious adverse events are shown in Table 5. Overall, there were 41 adverse events in 30 patients $(26.5 \%$ of patients experienced at least one adverse event).

Autoinflation was the most common problem seen at the early follow-up visits (14/113, 12.4\%).

Table 3 Subject satisfaction at 6 and 12 months

\begin{tabular}{|c|c|c|c|c|}
\hline \multirow[b]{2}{*}{ Question } & \multicolumn{2}{|c|}{6 months } & \multicolumn{2}{|c|}{12 months } \\
\hline & $\mathrm{N}$ & $\%(n / N)$ & $\mathrm{N}$ & $\%(n / N)$ \\
\hline \multicolumn{5}{|l|}{ Overall function } \\
\hline $\begin{array}{l}\text { Satisfactory and somewhat } \\
\text { satisfactory }\end{array}$ & 96 & $90.6(87 / 96)$ & 90 & $90(81 / 90)$ \\
\hline Neither & 96 & $2.1(2 / 96)$ & 90 & $1.1(1 / 90)$ \\
\hline \multicolumn{5}{|c|}{ Soft enough to conceal when deflated } \\
\hline $\begin{array}{l}\text { Satisfactory and somewhat } \\
\text { satisfactory }\end{array}$ & 96 & $76(73 / 96)$ & 90 & $82.2(74 / 90)$ \\
\hline Neither & 96 & $9.4(9 / 96)$ & 90 & $9.9(8 / 90)$ \\
\hline \multicolumn{5}{|c|}{ Ease of locating the deflation touch pads } \\
\hline $\begin{array}{l}\text { Satisfactory and somewhat } \\
\text { satisfactory }\end{array}$ & 96 & $78.2(75 / 96)$ & 89 & $77.6(69 / 89)$ \\
\hline Neither & 96 & $9.4(9 / 96)$ & 89 & $10.1(9 / 89)$ \\
\hline \multicolumn{5}{|l|}{ Ease of inflation } \\
\hline $\begin{array}{l}\text { Satisfactory and somewhat } \\
\text { satisfactory }\end{array}$ & 95 & $85.3(81 / 95)$ & 88 & $86.4(76 / 88)$ \\
\hline Neither & 95 & $7.4(7 / 95)$ & 88 & $6.8(6 / 88)$ \\
\hline \multicolumn{5}{|l|}{ Ease of deflation } \\
\hline $\begin{array}{l}\text { Satisfactory and somewhat } \\
\text { satisfactory }\end{array}$ & 96 & $70.8(68 / 96)$ & 90 & $73.3(66 / 90)$ \\
\hline Neither & 96 & $12.5(12 / 96)$ & 90 & $6.8(6 / 90)$ \\
\hline \multicolumn{5}{|c|}{ Hardness of erection when inflated } \\
\hline $\begin{array}{l}\text { Satisfactory and somewhat } \\
\text { satisfactory }\end{array}$ & 94 & $91.5(86 / 94)$ & 89 & $93.2(83 / 89)$ \\
\hline Neither & 94 & $4.3(4 / 94)$ & 89 & $2.3(2 / 89)$ \\
\hline \multicolumn{5}{|l|}{ Width when inflated } \\
\hline $\begin{array}{l}\text { Satisfactory and somewhat } \\
\text { satisfactory }\end{array}$ & 94 & $86.1(81 / 94)$ & 89 & $79.8(71 / 89)$ \\
\hline Neither & 94 & $5.3(5 / 94)$ & 89 & $10.1(9 / 89)$ \\
\hline \multicolumn{5}{|l|}{ Length when inflated } \\
\hline $\begin{array}{l}\text { Satisfactory and somewhat } \\
\text { satisfactory }\end{array}$ & 95 & $61.1(58 / 95)$ & 90 & $68.9(62 / 90)$ \\
\hline Neither & 95 & $9.5(9 / 95)$ & 90 & $7.8(7 / 90)$ \\
\hline
\end{tabular}

Would you recommend this penile implant device to men with the same erectile difficulty that you had?

$\begin{array}{llllll}\text { Yes and probably } & 96 & 86.5(83 / 96) & 90 & 87.8(79 / 90) \\ \text { Don't know } & 96 & 5.2(5 / 96) & 90 & 7.8(7 / 90)\end{array}$

If you had the decision to make again, would you undergo this penile implant procedure again?

\begin{tabular}{llclll} 
Yes and probably & 96 & $83.3(80 / 96)$ & 90 & $86.7(78 / 90)$ \\
Don't know & 96 & $9.4(9 / 96)$ & 90 & $7.8(7 / 90)$ \\
\hline
\end{tabular}


Table 4 Total adverse events (AEs)

\begin{tabular}{lcc}
\hline Adverse event & $\begin{array}{c}\text { Number } \\
\text { of AEs }\end{array}$ & \multicolumn{1}{l}{$\begin{array}{l}\text { Subjects with AE } \\
\%(\mathrm{n} / \mathrm{N})\end{array}$} \\
\hline Auto deflation & 2 & $1.8(2 / 113)$ \\
Auto inflation & 14 & $12.4(14 / 113)$ \\
Cylinder extrusion & 1 & $0.9(1 / 113)$ \\
Cylinder tips asymmetrical & 1 & $0.9(1 / 113)$ \\
Delayed wound healing & 2 & $1.8(2 / 113)$ \\
Device malfunction & 2 & $1.8(2 / 113)$ \\
Discomfort & 5 & $4.4(5 / 113)$ \\
Fever & 1 & $0.9(1 / 113)$ \\
Hematoma & 4 & $3.5(4 / 113)$ \\
Infection & 4 & $3.5(4 / 113)$ \\
Reservoir herniation & 1 & $0.9(1 / 113)$ \\
Pain-chronic & 1 & $0.9(1 / 113)$ \\
Penile edema & 1 & $0.9(1 / 113)$ \\
SST deformity & 2 & $1.8(2 / 113)$ \\
Total & 41 & $26.5(30 / 113)$ \\
\hline
\end{tabular}

SST = supersonic transport

However, 10 patients reporting autoinflation early on spontaneously resolved during the course of the study, leaving the final autoinflation rate of $3.5 \%$. Many other complications were minor and also resolved spontaneously.

Infection occurred in four devices and all of these devices were explanted. Two infections occurred at a single center and the other two occurred at two different centers. Therefore, we could not determine that infection was site-related. The small number of patients with infection did not allow any analysis of comorbidities that would put patients at risk for infection.

One patient with intractable chronic pain also had his device removed. Seven revision surgeries were performed, with successful resolution of the problem. Revisions were performed for device malfunction (2), discomfort (2), reservoir herniation (1), and scrotal hematoma (2). The investigators classified the two device malfunctions as device-related adverse events and the other revisions as procedure-related.

\section{Discussion}

IPPs are well-recognized treatments for ED. Previous studies have demonstrated high rates of

Table 5 Severe adverse events (SAEs)

\begin{tabular}{lll}
\hline SAE type & $\begin{array}{l}\text { Number } \\
\text { of SAEs }\end{array}$ & $\begin{array}{l}\text { Patients with SAE } \\
\%(\mathrm{n} / \mathrm{N})\end{array}$ \\
\hline Severe & & \\
$\quad$ Cylinder extrusion & 1 & $0.9(1 / 113)$ \\
$\quad$ Device malfunction & 2 & $1.8(2 / 113)$ \\
Hematoma & 2 & $1.8(2 / 113)$ \\
Infection & 4 & $3.5(4 / 113)$ \\
Pain-chronic & 1 & $0.9(1 / 113)$ \\
Total severe & 10 & $7.1(8 / 113)$ \\
\hline
\end{tabular}

patient satisfaction [7,10-12], although few studies have captured prospective data. The current study provides significant information on satisfaction captured throughout the first year after surgical implantation of the Titan OTR IPP. It offers unique data based on specific collection from invested parties including surgeons, trainers, partners, and patients.

While oral medications for ED have revolutionized the treatment paradigm, these therapies do not work for all patients. Likewise, other treatments, while highly effective for some, also do not provide correction of dysfunction for all $[12,13]$. Penile prostheses are reliable, effective devices that provide an alternative for men who wish to undergo surgical treatment of ED. However, understanding the issues related to satisfaction and managing patient expectations are critical for the implanting surgeon to recognize. Patients who have IPP surgery but are unable to operate the device afterward are particularly frustrated. Therefore, constant assessment and modification of existing devices is important to provide the best options for patients.

The Titan OTR IPP was conceived as a safe, effective device that is easier for patients to use. While the basic design of the cylinders and reservoir is well established as an effective product, the IPP pump is the part of the device that requires the most patient interaction and control. Creating a pump that allows for easy cylinder inflation and deflation is an important goal. The touch pads of the OTR pump allow for a singlesqueeze mechanism that is improved over the continuous manual pressure required for deflation of previous devices.

Improved ease of operation of the OTR pump was verified in a study of practitioners who perform penile prosthesis training in the clinic setting. In this study, an in vitro scrotal model with different pump designs was used to ask these individuals their opinions of pump designs. The OTR pump was found to be easier to operate over other pump designs, and the differences were statistically significant [14].

Prosthetic surgeons are generally interested in decreasing operative time. More efficient use of resources is accomplished by this and some believe that decreasing operative time may lead to improved outcomes. Factors that make device preparation easier can decrease operative time. In this study, implanting surgeons reported that device preparation was straightforward/simple $97 \%$ of the time. In $89 \%$ of the cases, the physician 
stated the pre-implant preparation was easier than other IPP pumps. These data reflect overall satisfaction with intraoperative device handling.

Likewise, postoperative training for IPP patients can require significant amounts of time. For Titan OTR study patients, training was completed around 6 weeks after implantation. The study represents one of the first to capture prospective data from those training the patient. With this pump design, the trainers reported that the process was easier than with previous IPP pumps in $96 \%$ of cases. The importance of ease of patient education for device use cannot be understated, as this will translate to less time required by the office staff, fewer remedial training sessions, and less frustration for patients. Indeed, Shaw and Garber demonstrated a statistically significant decrease in the number of training sessions required with the OTR pump, as compared with its predecessor [15].

Perhaps the most important measure of success after IPP implantation is that of patient satisfaction with use. Traditionally, IPP patient satisfaction rates have been around 90\% [16], and the current study again shows $>90 \%$ overall patient satisfaction at 6 and 12 months. Satisfaction regarding deflation with the OTR device in particular compares well with previous studies with $70.8 \%$ and $73.3 \%$ responding positively to this question at 6 and 12 months, respectively. At 12 months, the patient satisfaction with ease of deflation was statistically better than historical controls. One could argue that this is not clinically significant, because the difference between the ease of deflation and historical controls is modest. However, any improvement in the satisfaction of the patient undergoing implant surgery is an advance in prosthetic surgery.

It is possible that satisfaction rates may be affected by the type of disease present. For example, prior studies have suggested a lower rate of ED treatment satisfaction in men with Peyronie's disease. At the time of this writing, analysis by disease state has not yet been completed but is planned. Other factors that have recently been shown to affect postoperative satisfaction include reasonable preoperative expectations [17] and favorable female sexual function [18].

The adverse events identified in this study are well recognized in patients undergoing penile prosthetic surgery. In particular, early autoinflation was identified in $12.4 \%$, but most of these cases resolved spontaneously with no further intervention needed such that the autoinflation rate was $3.5 \%$ at the end of the study. This is similar to the rate of $4.3 \%$ identified in a previous study [19].

The number of infections in this study is higher than typically reported to implant company databases. Since report forms submitted to the implant companies are voluntary and incomplete, it is likely that underreporting of complications to such databases occurs. This study collected data prospectively and was complete. Nevertheless, the infection rate of $3.4 \%$ is higher than reported in recent publications, and may reflect the effects of a small number of patients presently included. More investigations are in order to assure that this infection rate does not represent the true infection rate of this device. Since the materials are unchanged from the previous devices, the authors believe that the high infection rate seen here will not be seen in future studies. Standardized antibiotic coating of the hydrophilic surface of the Titan device may help. Dhabuwala's group has suggested that rifampin and gentamicin may be the ideal choice of antibiotic solution [20].

This study represents one of the few prospective studies assessing penile implants. There are, however, several limitations of the trial. Due to staggered regulatory and Institutional Review Board (IRB) approvals of the protocol, several centers started surgical implantations earlier and entered higher subject numbers into the study. The comparison used for primary end point assessment relied on historical data. Furthermore, the comparator trials assessed satisfaction data that were collected at much later time intervals after surgery. If, for example, there is a progressive improvement over time in patient acceptance, the $64 \%$ cut point in ease of deflation may be too high when comparing with 6- and 12-month data. Indeed, in the current study there was an improvement in primary end point data between the 6-and 12-month marks.

Finally, it is important to recognize that there was no "head-to-head" comparisons in this trial, only historical controls from the literature. Ideally, a head-to-head comparison with two current devices would be interesting. Furthermore, identical questionnaires were not used in this and prior studies, possibly confounding the comparison. Also, the number of centers utilized in this study was few, and if extended to more cooperating centers in future studies, a stronger data set could be generated in future studies. An ideal comparator study would be a prospective, randomized large multicenter study comparing two different devices under the same conditions. 


\section{Conclusions}

In this prospective study, the Coloplast Titan OTR performed well in all measures of patient and clinician satisfaction. The device was felt by the implanters to be easier to prepare than the previous standard pump. The patient trainers found that it was easier to train patients in the operation of the device than previous devices, and this may lead to decreased training time and limitation of remedial training sessions. Finally, there was high satisfaction in all aspects of the device and higher satisfaction rates in the primary end point (ease of deflation) when compared with pooled historical controls at 12 months.

Corresponding Author: Dana A. Ohl, MD, A. Alfred Taubman Health Care Center, 1500 East Medical Center Drive, Ann Arbor, MI 48109-5330, USA. Tel: 734-232-4863; Fax: 734-763-4349; E-mail: daohl@ med.umich.edu

Funding: Coloplast Corp. (Minneapolis, MN) provided funding for this study.

Conflict of Interest: All authors were funded by Coloplast Corporation to complete this research, but received no direct personal benefit for this work.

\section{Statement of Authorship}

\section{Category 1}

(a) Conception and Design

Dana A. Ohl; Gerald Brock; David Ralph; William Bogache; LeRoy Jones; Ricardo Munarriz; Laurence Levine; Chad Ritenour

(b) Acquisition of Data Dana A. Ohl; Gerald Brock; David Ralph; William Bogache; LeRoy Jones; Ricardo Munarriz; Laurence Levine; Chad Ritenour

(c) Analysis and Interpretation of Data Dana A. Ohl; Chad Ritenour

\section{Category 2}

(a) Drafting the Article Dana A. Ohl; Chad Ritenour

(b) Revising It for Intellectual Content Dana A. Ohl; Gerald Brock; David Ralph; William Bogache; LeRoy Jones; Ricardo Munarriz; Laurence Levine; Chad Ritenour

\section{Category 3}

(a) Final Approval of the Completed Article Dana A. Ohl; Gerald Brock; David Ralph; William Bogache; LeRoy Jones; Ricardo Munarriz; Laurence Levine; Chad Ritenour

\section{References}

1 Feldman HA, Goldstein I, Hatzichristou DG, Krane RJ, McKinlay JB. Impotence and its medical and psychosocial correlates: Results of the Massachusetts Male Aging Study. J Urol 1994;151:54-61.

2 Laumann EO, Paik A, Rosen RC. Sexual dysfunction in the United States: Prevalence and predictors. JAMA 1999;281: 537-44.

3 Morales A, Gingell C, Collins M, Wicker PA, Osterloh IH. Clinical safety of oral sildenafil citrate (VIAGRA) in the treatment of erectile dysfunction. Int J Impot Res 1998;10:69-73.

4 Costabile RA. Pharmacological therapy for the treatment of sexual dysfunction-are we there yet? J Urol 2008;179:819-20.

5 McVary KT. Clinical practice. Erectile dysfunction. N Engl J Med 2007;357:2472-81.

6 Scott FB, Byrd GJ, Karacan I, Olsson P, Beutler LE, Attia SL. Erectile impotence treated with an implantable, inflatable prosthesis. Five years of clinical experience. JAMA 1979;241: 2609-12.

7 Wilson SK, Cleves MA, Delk JR 2nd. Comparison of mechanical reliability of original and enhanced Mentor Alpha I penile prosthesis. J Urol 1999;162:715-8.

8 Daitch JA, Angermeier KW, Lakin MM, Ingleright BJ, Montague DK. Long-term mechanical reliability of AMS 700 series inflatable penile prostheses: Comparison of CX/CXM and Ultrex cylinders. J Urol 1997;158:1400-2.

9 Brinkman MJ, Henry GD, Wilson SK, Delk JR 2nd, Denny GA, Young M, Cleves MA. A survey of patients with inflatable penile prostheses for satisfaction. J Urol 2005;174:253-7.

10 Goldstein I, Newman L, Baum N, Brooks M, Chaikin L, Goldberg K, McBride A, Krane RJ. Safety and efficacy outcome of Mentor alpha-1 inflatable penile prosthesis implantation for impotence treatment. J Urol 1997;157:833-9.

11 Jensen JB, Madsen SS, Larsen EH, Jensen KM, Kirkeby HJ. Patient and partner satisfaction with the Mentor Alpha-1 inflatable penile prosthesis. Scand J Urol Nephrol 2005;39:66-8.

12 Hellstrom WJG, Montague DK, Moncada I, Carson C, Minhas S, Faria G, Krishnamurti S. Implants, mechanical devices, and vascular surgery for erectile dysfunction. J Sex Med 2010;7:501-23.

13 Hatzimouratidis K, Hatzichristou DG. A comparative review of the options for treatment of erectile dysfunction: Which treatment for which patient? Drugs 2005;65:1621-50.

14 Quallich SA, Ohl DA, Dunn RL. Evaluation of three penile prosthesis pump designs in a blinded survey of practitioners. Urol Nurs 2008;28:101-5.

15 Shaw T, Garber BB. Coloplast Titan inflatable penile prosthesis with One-Touch Release pump: Review of 100 cases and comparison with Genesis pump. J Sex Med 2011;8:310-4.

16 Rajpurkar A, Dhabuwala CB. Comparison of satisfaction rates and erectile function in patients treated with sildenafil, intracavernous prostaglandin E1 and penile implant surgery for erectile dysfunction in urology practice. J Urol 2003;170:159-263.

17 Kramer AC, Schweber A. Patient expectations prior to Coloplast Titan penile prosthesis implant predicts postoperative satisfaction. J Sex Med 2010;7:2261-6.

18 Moscovic DJ, Gittens P, Avila D, Chandrashekar A, Khera M, Lipshultz LI. Favorable female sexual function is associated with patient satisfaction after inflatable penile prosthesis implantation. J Sex Med 2011;8:1996-2001.

19 Hollenbeck BK, Miller DC, Ohl DA. The utility of lockout valve reservoirs in preventing autoinflation in penile prostheses. Int Urol Nephrol 2002;34:379-83.

20 Dhabuwala C, Sheth S, Zamzow B. Infection rates of rifampin/ gentamicin-coated Titan Coloplast penile implants. Comparision with Inhibizone-impregnated AMS penile implants. J Sex Med 2011;8:315-20. 